\title{
Fragmentation Reduction through Farmer-Led Land Transfer and Consolidation? Experiences of Rice Farmers in Wuhan Metropolitan Area, China
}

\author{
Chaozheng Zhang and Danling Chen * \\ College of Public Administration, Huazhong Agricultural University, Wuhan 430070, China; \\ hailun_12@webmail.hzau.edu.cn \\ * Correspondence: danlingchen@mail.hzau.edu.cn
}

Citation: Zhang, C.; Chen, D. Fragmentation Reduction through Farmer-Led Land Transfer and Consolidation? Experiences of Rice Farmers in Wuhan Metropolitan Area, China. Agriculture 2021, 11, 631. https: / / doi.org/10.3390/ agriculture11070631

Academic Editors: Vítor João Pereira Domingues Martinho, Paulo Reis Mourão and Nikolaos Georgantzis

Received: 9 June 2021

Accepted: 4 July 2021

Published: 6 July 2021

Publisher's Note: MDPI stays neutral with regard to jurisdictional claims in published maps and institutional affiliations.

Copyright: (c) 2021 by the authors. Licensee MDPI, Basel, Switzerland. This article is an open access article distributed under the terms and conditions of the Creative Commons Attribution (CC BY) license (https:// creativecommons.org/licenses/by/ $4.0 /)$.

\begin{abstract}
Land fragmentation has become a serious obstacle to agricultural production, and land transfer and consolidation are traditionally emphasized as the two most effective solutions to this quandary. To identify the extent of land fragmentation accurately and systematically, this study selected the number of plots, the average size of plots, and the average distance between plots to calculate the land fragmentation index (LFI). Taking the Wuhan metropolitan area as a case study, this study examined the effectiveness of farmer-led land transfer and consolidation on land fragmentation. The main results are as follows: (a) most of the transferred plots and contracted plots were not spatially adjacent, suggesting that the tenants could not merge and consolidate both plots; (b) land transfer caused the LFI to increase by $2.85 \%$, suggesting that land transfer had intensified the degree of land fragmentation to some extent; (c) if the transferred and contracted plots were non-adjacent or adjacent but unmerged and unconsolidated, then the LFI might increase or decrease; (d) if the transferred and contracted plots were spatially adjacent, merged, and consolidated, then the LFI decreased significantly.
\end{abstract}

Keywords: land transfer; land consolidation; land fragmentation; farmer-led

\section{Introduction}

Land fragmentation (LF) is a universal trait of all agricultural systems that affects farmland productivity, and as yet, no one has documented a rural society where there was no LF [1]. LF is a complex concept that encompasses four aspects: (i) number of plots; (ii) sizes of plots; (iii) shape of plots; and (iv) distances between plots, or distance between plots and homesteads [2-4]. Fragmented landholding exerts both positive and negative effects on agricultural performance. On the one hand, it may increase the utilization of labor resources, optimize the internal structure of planting agriculture, and disperse the natural and market risks in production process [5-10]. On the other hand, it may hinder the use of agricultural machinery, increase the costs of agricultural production, arouse the dispute over land ownership, and lessen the marginal productivity of agricultural labor [11-16].

As a largely agricultural country with a huge but economically poor rural population, China is confronted by highly severe LF in its rural areas [14,17]. The Household Contract Responsibility System (HCRS) implemented in 1978 contributed to rapid rural and agricultural development by stimulating the farmers' enthusiasm for agricultural production, but also led to each household having possession of numerous small and separate plots of cultivated land $[10,18]$. According to a report from the Rural Fixed Observation Point of the Ministry of Agriculture in China, the average number of plots per household declined obviously during 2000 to 2015, but the average size of plots per household did not increase accordingly [18]. This finding is somewhat unexpected and concerning.

With the continuous progress of agricultural modernization and mechanization, it has been generally believed that the negative effects of LF have become increasingly obvious 
and intolerable $[9,15]$. Accordingly, numerous policies for land transfer and consolidation have been implemented to avoid the negative externalities of LF in Asian countries such as China and Vietnam, as well as European countries such as France and Germany [19-29]. The willingness to increase the scale of land management and to reduce the degree of LF promotes the emergence of the land transfer market, which is conducive to achieving a moderate scale of land management and optimizing the allocation of labor and capital, thereby improving agricultural productivity and income $[25,29]$. However, whether land transfer results in defragmentation is controversial. Lohmar et al. [30] and Deininger et al. [31] found that farmer-dominated patterns of land transfer have high transaction costs, short transfer periods, and no formal contracts, so it is practically impossible to increase the scale of land management and reduce LF. In contrast, patterns of land transfer dominated by village collectives have low transaction costs, long transfer periods, and formal contracts, so it is possible to increase the scale of land management and achieve defragmentation. Ma et al. [32] and Wang et al. [33] argue that land has irreplaceable and indivisible social functions, such as employment, pensions, and medical insurance, for farmers, but unmatched land plots and long chains of exchanges result in transaction costs greater than the costs of the scale of land management. Thus, both patterns of land transfer have little effect on reducing LF.

Land consolidation is widely considered to be the most direct and effective solution to the problem of LF, and its original purpose is to increase the effective area and improve the comprehensive quality of cultivated land $[18,20]$. With the implementation of land consolidation, land leveling projects can solve the physical fragmentation and land tenure adjustment and solve the ownership fragmentation, while the organic combination of the two can effectively control the problem of LF $[18,34,35]$. A land leveling project refers to the field construction and soil maintenance measures implemented to meet the needs of farmland cultivation, irrigation and drainage; it includes a farming field construction project and farming layer soil conservation project. However, land consolidation aimed at preventing LF has been largely unsuccessful in South Asia for various reasons, including political, economic, and cultural factors [36]. For example, Liu et al. [37] and Niroula et al. [38] found that strong sentimental attachments to land parcels caused landowners to resist land tenure adjustment strongly. To avoid conflict and accelerate progress, project constructors usually ignore the land tenure adjustment deliberately. Therefore, land consolidation has not yielded satisfactory outcomes. Most studies have focused on the effects of land transfer or land consolidation on LF, but have not paid much attention to their joint effects, and no sufficient evidence exists for the effectiveness of farmer-led patterns of land transfer and consolidation.

At the end of 2019, the transfer area of China's household contracted land reached 37 million hectares, accounting for $40.1 \%$ of the total area of household contracted land. This area was $143.42 \%$ higher than it was in 2011. However, land transfer is still mainly conducted among farmers [38]. Farmers are and will remain the main force in land management and the core subject of fragmentation treatment for a long time to come [39]. Taking the Wuhan metropolitan area as a case study, this study examined the effectiveness of farmer-led land transfer and consolidation on LF. Therefore, the contributions of this study derived from the following three procedures. First, according to the attribute characteristics of LF, we selected the number of plots, the average size of plots, and the average distance between the plots as comprehensive measurement indicators of LF in its various dimensions. Second, we drew upon expert grading methods to select particular farmers to be the experts who determined the weights of the measurement indicators of land fragmentation index (LFI). Third, using the paired sample $t$-test, we examined the effectiveness of the farmer-led pattern of land transfer and consolidation of LF in three scenarios. 


\section{Materials and Methods}

\subsection{Theoretical Analysis and Hypotheses}

To analyze the effectiveness of farmer-led land transfer and consolidation on LF, the first step is to clarify how to measure the degree of LF. There are two main methods for measuring the degree of LF: the single index method and comprehensive index method [7,12]. The single index method usually uses the number of plots, the average size of plots, and the average distance between plots or the average distance between plots and homesteads. It is straightforward and easy to understand, but too one-sided. The comprehensive index method combines information from individual indexes. Simpson's, Januszewski's, and Igbozurike's indexes are the three most commonly used comprehensive indexes $[1,14,15]$. Simpson's and Januszewski's indexes combine information on the number and sizes of plots but have difficulty discerning which indicator is the dominant one and ignore the distances between plots or the distances between plots and homesteads. Although Igbozurike's index introduces the variable of distance, the regulation of distance is rather vague, so scholars vary in their adoption of the distances between plots or between plots and homesteads. In sum, the traditional indexes are not always suitable, so there is a need for new indexes.

The selection of the measurement indicators of the degree of LF should be based on the characteristics of LF, namely, the number, sizes, and distribution of plots. It is worth noting that the distribution of plots is derived from the distances of each plot to other plots, but the distances between plots and homesteads cannot accurately reflect the spatial distribution of the plots. Therefore, we selected the number of plots $(n)$, the average size of plots $(a)$, and the average distance between plots $(d)$ as the measurement indicators of the degree of LF. Next, we introduced the farmers' grading method to determine the weight coefficients of the three individual indicators and employed the comprehensive index method to calculate the LFI. Because the individual indicators have inconsistent scales or distributions, we normalized the data by the minimum-maximum standardization method, for which $a$ is a negative indicator, whereas $n$ and $d$ are positive indicators. $\hat{n}, \hat{a}$, and $\hat{d}$ are their respective normalized values while $w_{1}, w_{2}$ and $w_{3}$ are their respective weight coefficients. The formula for LFI can be expressed as:

$$
L F I_{\mathrm{it}}=w_{1} \hat{n}_{\mathrm{it}}+w_{2} \hat{a}_{\mathrm{it}}+w_{3} \hat{d}_{\mathrm{it}}
$$

where $L F I_{i t}$ represents the LFI of $i$-th farmer at year $t$, whose value ranges from 0 to 1 . The closer the value to 1 , the higher is the degree of LF and vice versa.

The livelihoods of the landlord (whose plots have been transferred-out) are less dependent on agricultural production; hence this study focused on the coupling effects of farmer-dominated land transfer and consolidation on the fragmentation degree of the tenants (whose plots have been transferred-in from the landlord). $n_{i 0}, a_{i 0}$, and $d_{i 0}$ represent the number of plots, the average size of plots, and the average distance between plots, respectively, before land transfer and consolidation, whereas $n_{i 1}, a_{i 1}$, and $d_{i 1}$ represent the respective values after land transfer and consolidation. To ensure the comparability of the degree of LF, all the values before and after land transfer and consolidation are combined for normalization. The respective normalized values are represented by $\hat{n}_{i 0}, \hat{a}_{i 0}$, and $\hat{d}_{i 0}$, then by $\hat{n}_{i 1}, \hat{a}_{i 1}$, and $\hat{d}_{i 1}$ after land transfer and consolidation. Therefore, the LFIs before and after land transfer and consolidation are $L F I_{i 0}$ and $L F I_{i 1}$, respectively.

Now, we discuss three scenarios below for the coupling effects of land transfer and consolidation on LF.

Scenario 1: The transferred and contracted plots are not spatially adjacent, so the tenants are unable to merge and consolidate their transferred and contracted plots. Hence, the number of plots operated by the tenants increases $\left(\hat{n}_{i 1}-\hat{n}_{i 0}>0\right)$. Since the number and sizes of the transferred plots cannot be determined, the average size of the plots operated by the tenants may increase or decrease, so $\left(\hat{a}_{i 1}-\hat{a}_{i 0}\right)$ cannot be determined. Because the transferred and contracted plots are not spatially adjacent, the average distance between 
plots may shorten or extend, so $\left(\hat{d}_{i 1}-\hat{d}_{i 0}\right)$. Since $w_{1}\left(\hat{n}_{i 1}-\hat{n}_{i 0}\right)>0$ but $w_{2}\left(\hat{a}_{i 1}-\hat{a}_{i 0}\right)$ and $w_{3}\left(\hat{d}_{i 1}-\hat{d}_{i 0}\right)$ cannot be determined, $L F I_{i 1}-L F I_{i 0}$ is also uncertain.

Scenario 2: The transferred and contracted plots are spatially adjacent but have not been merged and consolidated. The possible outcomes of Scenario 2 are similar to those of Scenario 1, e.g., the number of plots operated by the tenants increases, but the sizes of the plots and the average distance between the plots operated by the tenants cannot be determined. Therefore, $L F I_{i 1}-L F I_{i 0}$ is also uncertain.

Scenario 3: The transferred and contracted plots are spatially adjacent, so they have been partially or completely merged and consolidated. The possible outcomes are also similar to those of Scenarios 1 and 2. With complete merging and consolidation, the number of plots operated by the tenants may remain unchanged or decrease $\left(\hat{n}_{i 1}-\hat{n}_{i 0} \leq 0\right)$, the average size of the plots operated by the tenants increases $\left(\hat{a}_{i 1}-\hat{a}_{i 0}<0\right)$, and the average distance between plots operated by the tenants may become shorter or remain unchanged $\left(\hat{d}_{i 1}-\hat{d}_{i 0} \leq 0\right)$. Since $w_{1}\left(\hat{n}_{i 1}-\hat{n}_{i 0}\right) \leq 0, w_{2}\left(\hat{a}_{i 1}-\hat{a}_{i 0}\right)<0$, and $w_{3}\left(\hat{d}_{i 1}-\hat{d}_{i 0}\right) \leq 0$, then $L F I_{i 1}-L F I_{i 0}<0$.

Based on the above analysis, the following hypothesis can be put forward: land transfer affects LF, but the direction of its action depends on the spatial relationship between contracted and transferred plots, as well as on the extent of merging and consolidation. Only when transferred and contracted plots are spatially adjacent, as well as completely merged and consolidated, can land transfer effectively reduce the degree of LF.

\subsection{Study Area}

Consisting of one provincial capital city, five prefecture-level cities, and three countylevel cities, the Wuhan metropolitan area is located in the central-eastern part of Hubei province (Figure 1). The Wuhan metropolitan area accounts for only $31.2 \%$ of the total area of Hubei province but constituted $53.8 \%$ of the total population and $60.3 \%$ of the province's gross domestic product (GDP) in 2020 [40]. It possesses a varied and complicated topography with plains, hills, and mountains, which account for $50 \%, 30 \%$, and $20 \%$, respectively, of the total area [41]. However, the widespread conversion of cultivated land to construction land has intensified LF across the region and has strongly affected agricultural production [42].

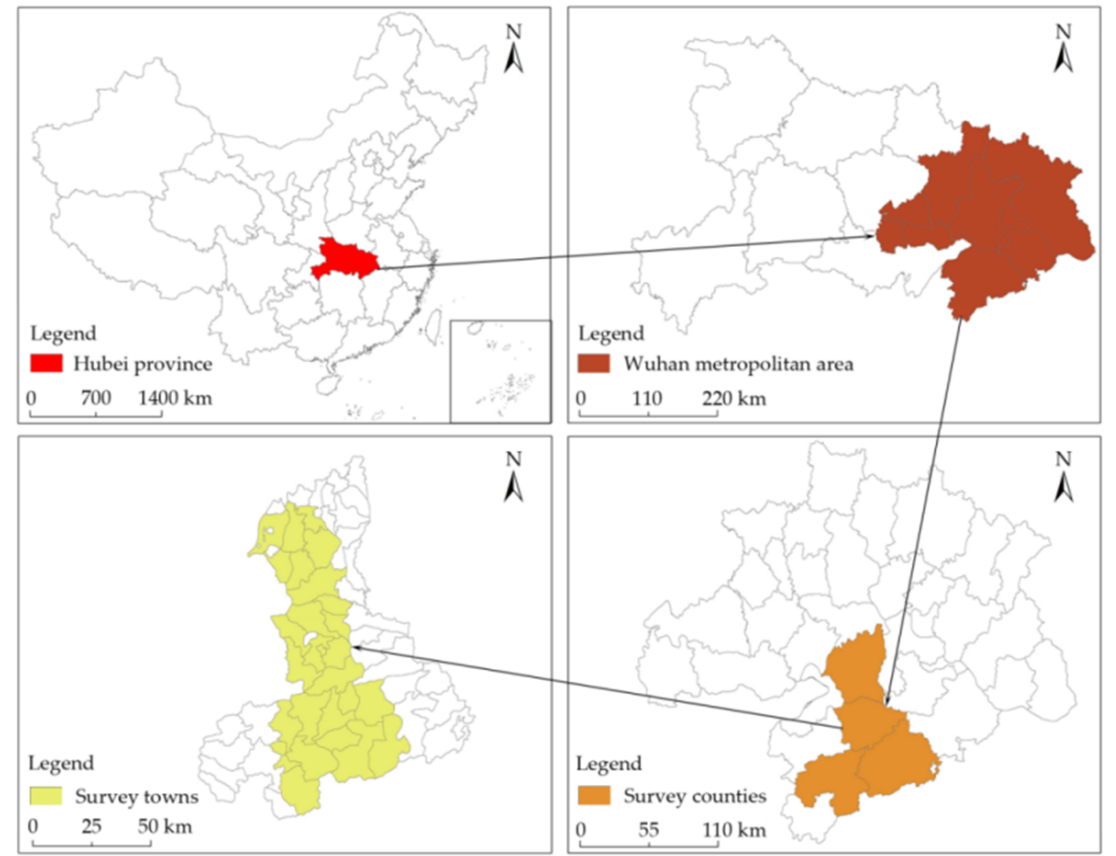

Figure 1. Study area. 


\subsection{Methods}

\subsubsection{Paired Sample $t$-Test}

A paired sample $t$-test is used to determine whether there is statistical evidence that the mean difference between paired observations on a particular outcome is not equal to zero [43]. This test emphasizes homogeneous test subjects to ensure that the influences of other variables are eliminated so that the relationships between the independent variable and the dependent variables are better represented [44]. Since there are only 138 samples of tenants, it is not suitable to employ regression analysis method to conduct quantitative testing, but it is possible to use paired sample $t$-test to carry out statistical testing [45]. By comparing whether the mean difference of the LFIs before and after land transfer and consolidation were significantly far from zero, we were able to deduce if land transfer and consolidation had reduced the degree of LF.

\subsubsection{Farmers Grading Method}

Drawing on expert grading methods, farmers can be selected as the experts who determine the weight coefficients of the measurement indicators of the degree of LF. To ensure the credibility of the farmers' grading, our questionnaires were mainly given to those familiar with the situations of land management and agricultural production. Based on the survey data collected from 775 rice farmers, we summarized the farmers' ratings of the three indicators affecting agricultural production, and the $n_{i t}, a_{i t}$ and $d_{i t}$ have obtained score of 2996, 2974 and 2978, respectively (Table 1). The weights of each indicator is equal to the score of each indictor divided by the total scores of the three indicators. Therefore, the weights of $n_{i t}, a_{i t}$ and $d_{i t}$ were $0.335,0.332$, and 0.333 , respectively. The formula for LFI can be expressed as follows:

$$
L F I_{\mathrm{it}}=0.335 \hat{n}_{\mathrm{it}}+0.332 \hat{a}_{\mathrm{it}}+0.333 \hat{d}_{\mathrm{it}}
$$

Table 1. Weights coefficient of measurement indicators of LFI.

\begin{tabular}{|c|c|c|c|c|c|c|}
\hline Indicator & Description & Grading & Sum & Mean & Std. Dev. & Weight \\
\hline$n_{i t}$ & $\begin{array}{l}\text { The more the number of plots, } \\
\text { the more inconvenient it is to } \\
\text { agricultural production }\end{array}$ & \multirow{3}{*}{$\begin{array}{c}\text { Agree completely }=5 ; \\
\text { Mostly agree }=4 ; \\
\text { Agree to some extent }=3 ; \\
\text { Agree a little }=2 ; \\
\text { Disagree completely }=1\end{array}$} & 2996 & 3.866 & 1.081 & 0.335 \\
\hline$a_{i t}$ & $\begin{array}{l}\text { The smaller the average size of } \\
\text { plots, the more inconvenient it } \\
\text { is to agricultural production }\end{array}$ & & 2974 & 3.837 & 1.073 & 0.332 \\
\hline$d_{i t}$ & $\begin{array}{l}\text { The further the average } \\
\text { distance between plots, the } \\
\text { more inconvenient it is to } \\
\text { agricultural production }\end{array}$ & & 2978 & 3.843 & 1.142 & 0.333 \\
\hline
\end{tabular}

\subsection{Data Source}

The data were collected by a survey questionnaire presented to rice farmers in the Wuhan metropolitan area. According to the principle of relative equilibrium and random sampling, 7, 9, 6, and 5 towns in Jiangxia District, Xian'an District, Tongshan County, and Chongyang County, respectively, were selected for the survey. In each town, 3 to 5 villages were selected, and in each village, 10 to 20 rice farmers were selected as the subjects. After excluding 146 invalid samples, in which rice had not been planted, we obtained 775 valid samples from 97 villages in 27 towns in 4 counties. The valid samples of landlords, tenants, and contractors (who neither transferred-out nor transferred-in land) were 56, 138, and 581, respectively. The sample data were tested for reliability and validity before data processing. The results showed that the Cronbach's Alpha coefficient is 0.764, greater than 0.7; the Kaiser-Meyer-Olin value is 0.685, higher than 0.6; the spherical degree of Bartlett's test for sig. value is 0 , at 0.01 significant level, indicating that the questionnaire is highly reliable. 


\section{Results}

3.1. Descriptive Analysis

\subsubsection{Spatial Characteristics of Contracted Land Fragmentation}

Since the surveyed area is in the transition zone from plain to hilly and mountain, there is much difficulty in distinguishing between hillocks and plains, and low mountains and hills. Hence, the landform types of the study area are finally divided into two categories: low hillock and plain, low mountain and hill. Table 2 shows the regional difference in the fragmentation degree of contracted land. The average LFI value of the survey areas is 0.376 , and the average LFI value of low mountain and hill areas is $3.78 \%$ higher than that of low hillock and plain areas. In terms of individual indicator, although the average number of plots in low mountain and hill areas is $12.62 \%$ less than that of low hillock and plain areas, the average size of plots is $34.94 \%$ smaller than that of low hillock and plain areas, and the average distance between plots is $8.26 \%$ greater than that of low hillock and plain areas. These implies that the LF in low mountain and hill areas is more severe than that in low hillock and plain areas.

Figure 2 depicts the spatial distribution of LF degree in different landform types. Grading similar individual index value and comprehensive index value of LF into the same group is conducive to comparison. Therefore, using the Jenks natural breaks classification method in ArcGIS, the individual and comprehensive index value of LF were divided into three groups: low, medium, and high. As shown in Figure 2, towns with high and medium LFI value were mostly concentrated in low mountain and hill areas. In terms of single index, towns with the largest average number of plots but largest and medium average size of plots are mostly scattered in low hillock and plain areas, while towns with the furthest average distance between plots were mainly located in low mountain and hill areas.

Table 2. Regional distribution of LF degree in different landform types.

\begin{tabular}{lcccc}
\hline & $\boldsymbol{L F I}_{\boldsymbol{i t}}$ & $\boldsymbol{n}_{\boldsymbol{i t}}$ & $\boldsymbol{a}_{\boldsymbol{i t}} /$ Hectares & $\boldsymbol{d}_{\boldsymbol{i t}} / \mathbf{m}$ \\
\hline Survey Area & 0.376 & 5.103 & 0.070 & 410.462 \\
$\bullet \quad$ Low hillock and plain areas & 0.370 & 5.404 & 0.083 & 394.780 \\
- Low mountain and hilly areas & 0.384 & 4.722 & 0.054 & 430.316 \\
\hline
\end{tabular}

\subsubsection{Relationship between Transferred Plots and Contracted Pots}

Table 3 shows the relationship between the transferred plots and the contracted plots. The results show that only $37.68 \%$ of the transferred plots are adjacent to the contracted plots. Of the adjacent plots, only $28.85 \%$ have been merged and consolidated.

Table 3. Spatial relationships and mergers between transferred and contracted plots.

\begin{tabular}{lcc}
\hline Spatial Relationships and Mergers & Sample & Proportion \\
\hline Spatially adjacent transferred and contracted plots & 52 & $37.68 \%$ \\
- Merged and consolidated & 15 & $28.85 \%$ \\
- Unmerged and unconsolidated & 37 & $71.15 \%$ \\
Non-adjacent transferred and contracted plots & 86 & $62.32 \%$ \\
\hline
\end{tabular}

\subsubsection{Changes in Degree of LF before and after Land Transfer}

Table 4 represents the changes in the degree of LF before and after land transfer. The LFI after land transfer increased by 0.011 with an increased rate of $2.85 \%$. In terms of individual indicators, the average number of plots increased by 3.043 with an increased rate of $66.44 \%$, the average size of plots increased by 0.017 hectares with an increased rate of $23.61 \%$, and the average distance between plots increased by $17.816 \mathrm{~m}$ with an increased rate of $4.13 \%$. These findings imply that land transfer has not reduced the degree of LF but has increased the degree of LF to some extent. The main reasons are the non-adjacency of most of the transferred plots. Even for adjacent plots, the issue of land ownership and 
the normalization of land transfer hindered the tenants' abilities to merge and consolidate them.

Table 4. Changes of LF before and after land transfer.

\begin{tabular}{ccccc}
\hline & Before & After & Change Value & Change Rate \\
\hline$L F I_{i t}$ & 0.386 & 0.397 & 0.011 & $2.85 \%$ \\
$n_{i t}$ & 4.580 & 7.623 & 3.043 & $66.44 \%$ \\
$a_{i t} /$ hectares & 0.072 & 0.089 & 0.017 & $23.61 \%$ \\
$d_{i t} / \mathrm{m}$ & 431.242 & 449.058 & 17.816 & $4.13 \%$ \\
\hline
\end{tabular}

\subsubsection{Relationship between Scale of Land Management and Degree of LF}

Figure 3 describes the relationship between the scale of land management and the degree of LF. No obvious linear relationship exists before land transfer, but a negative correlation that does not pass the significance test appears after land transfer. These findings reveal neither positive nor negative relationships.

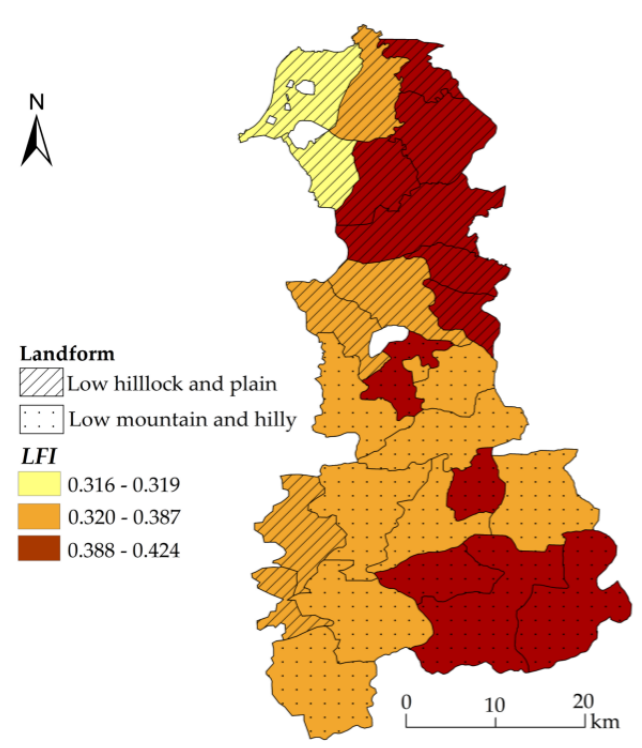

(a)

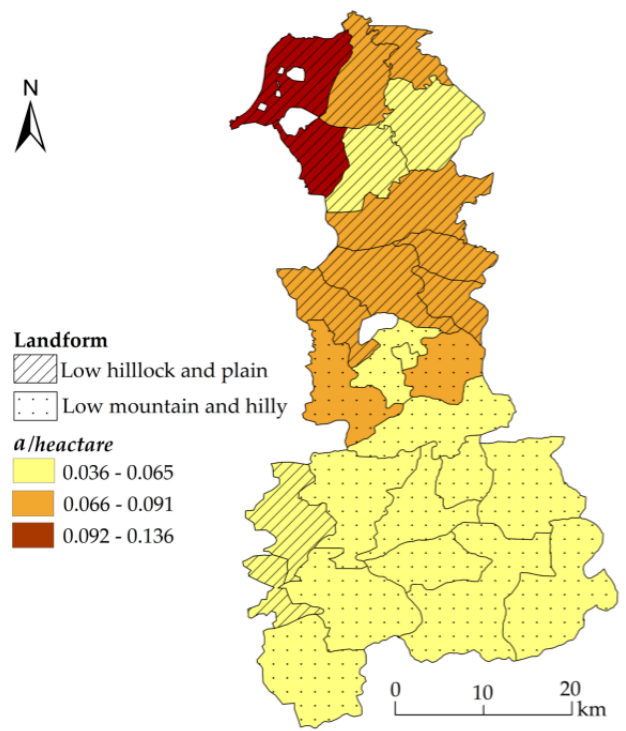

(c)

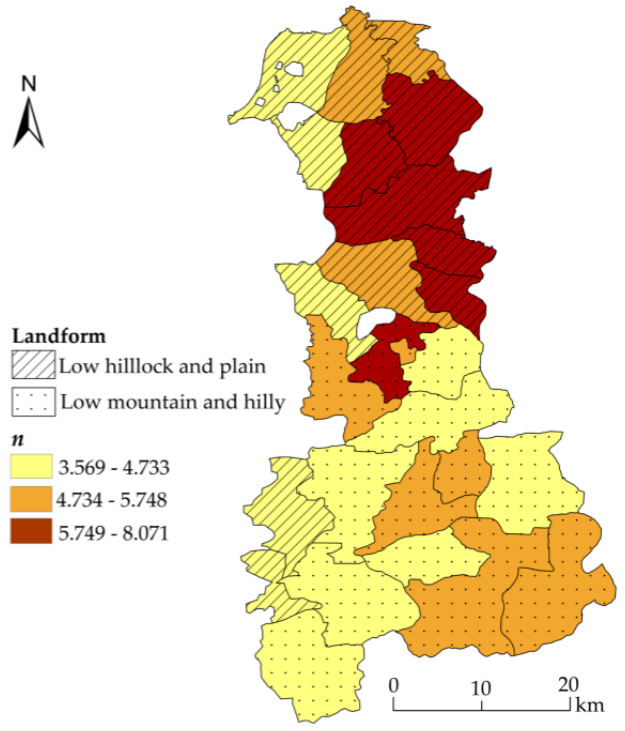

(b)

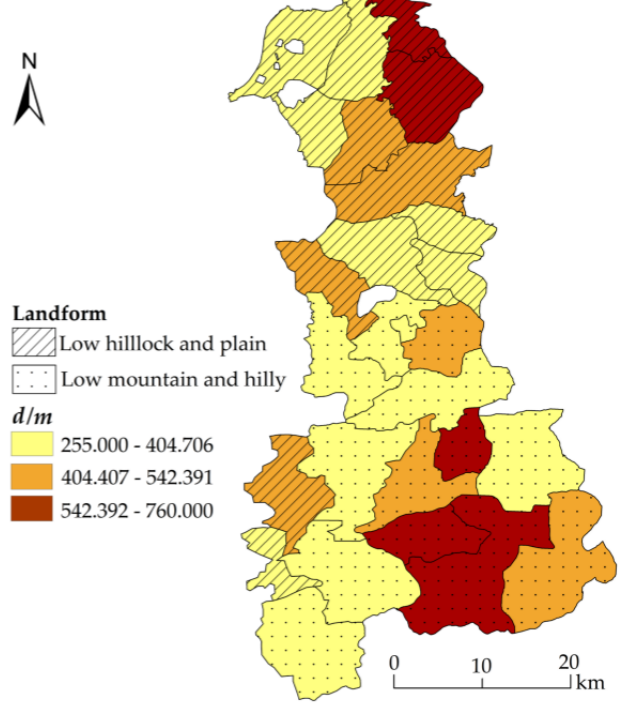

(d)

Figure 2. Spatial distribution of LF degree in different landform types: (a) the average LFI; (b) the average number of plots; (c) the average size of plots; (d) the average distance between plots. 


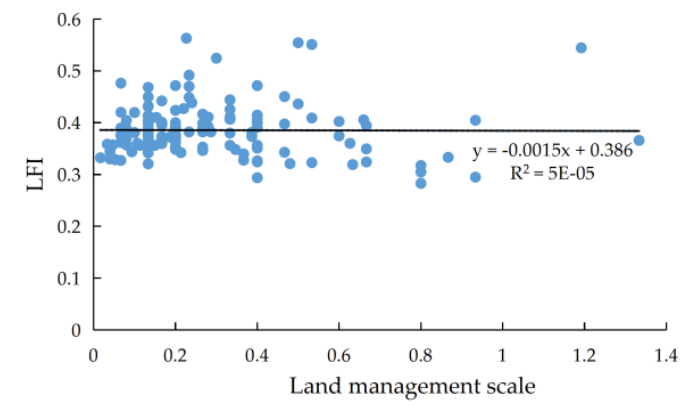

(a)

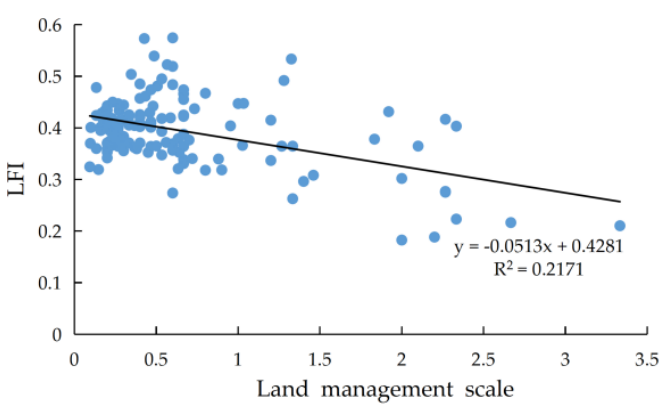

(b)

Figure 3. Relationship between scale of land management and degree of LF: (a) before transfer; (b) after transfer.

To further reveal the relationship between the scale of land management and the degree of LF, the group average clustering method was used to divide the rice farmers into three groups: small-scale farmers ( $<0.5$ hectares), medium-scale farmers ( $0.5-1$ hectares), and large-scale farmers ( $\geq 1$ hectare). As shown in Table 5, before land transfer, the large-scale farmers had the highest LFI, followed by the small-scale farmers, then by the medium-scale farmers. After land transfer, the small-scale farmers had the highest LFI, followed by the medium-scale farmers, then by the large-scale farmers. These results are consistent with the findings in Figure 3. However, when the small- and medium-scale farmers transformed into large-scale farmers, the LFI was significantly reduced, indicating that rice farmers paid close attention to the reduction of LF in the pursuit of moderate scales of operation.

Table 5. Relationship between scale of land management and degree of LF.

\begin{tabular}{|c|c|c|c|c|c|c|c|c|c|c|}
\hline \multirow{2}{*}{\multicolumn{2}{|c|}{ Land Management Scale }} & \multirow{3}{*}{ Samples } & \multicolumn{8}{|c|}{ LF DEGREE } \\
\hline & & & \multicolumn{2}{|c|}{$L F I_{i t}$} & \multicolumn{2}{|c|}{$n_{i t}$} & \multicolumn{2}{|c|}{$a_{i t}$} & \multicolumn{2}{|c|}{$d_{i t}$} \\
\hline Before & After & & Before & After & Before & After & Before & After & Before & After \\
\hline Small & Small & 76 & 0.386 & 0.410 & 3.082 & 6.053 & 0.046 & 0.055 & 406.184 & 460.711 \\
\hline Small & Medium & 29 & 0.391 & 0.410 & 4.828 & 8.552 & 0.078 & 0.086 & 508.155 & 459.310 \\
\hline Small & Large & 12 & 0.376 & 0.346 & 3.750 & 11.917 & 0.091 & 0.161 & 426.667 & 429.091 \\
\hline Medium & Medium & 9 & 0.418 & 0.396 & 8.667 & 8.556 & 0.086 & 0.150 & 441.667 & 376.667 \\
\hline Medium & Large & 10 & 0.338 & 0.306 & 4.800 & 10 & 0.210 & 0.225 & 393 & 425 \\
\hline Large & Large & 2 & 0.455 & 0.468 & 16 & 21 & 0.085 & 0.088 & 440 & 400 \\
\hline
\end{tabular}

\subsection{Statistical Test}

\subsubsection{Test for Scenario 1}

Table 6 summarizes the results of the paired sample $t$-tests for the change in the degree of LF in Scenario 1. Regardless of an increase or decrease in the degree of LF, the correlation coefficients of the LFI and the three individual indicators are greater than 0.67 and pass the significance test, indicating a significant correlation between the data before and after land transfer, so the paired sample $t$-test can be employed.

Consistent with the theoretical analysis, the $t$-tests confirm that the LFI in Scenario 1 may increase or decrease. Specifically, the number and average size of plots increase, whereas the average distance between plots may shorten or lengthen. Since the transferred plots are not adjacent to the contracted plots, the tenants are unable to merge and consolidate them. The change in the average distance between the plots is uncertain. Both situations lead to unsatisfactory outcomes for land transfer in the solution to LF. 
Table 6. Results of paired sample t-test for change of LF degree in scenario 1.

\begin{tabular}{|c|c|c|c|c|c|c|c|c|}
\hline & \multirow{2}{*}{$L F I_{i t}$} & \multicolumn{3}{|c|}{ Paired Samples Correlations } & \multicolumn{4}{|c|}{ Paired Sample Differences } \\
\hline & & Samples & Correlation & Sig. & Mean & Std. Dev. & $t$-Value & Sig. \\
\hline \multirow{4}{*}{ Increase } & $L F I_{i 1}-L F I_{i 0}$ & \multirow{4}{*}{65} & $0.805^{* * *}$ & 0.000 & $0.037^{* * *}$ & 0.025 & 11.758 & 0.000 \\
\hline & $n_{i 1}-n_{i 0}$ & & $0.789^{* * *}$ & 0.000 & $3.492 * * *$ & 2.575 & 10.936 & 0.000 \\
\hline & $a_{i 1}-a_{i 0}$ & & $0.673^{* * *}$ & 0.000 & 0.002 & 0.039 & 0.393 & 0.695 \\
\hline & $d_{i 1}-d_{i 0}$ & & $0.739 * * *$ & 0.000 & $187.077^{* * *}$ & 253.560 & 5.948 & 0.000 \\
\hline \multirow{4}{*}{ Decrease } & $L F I_{i 1}-L F I_{i 0}$ & \multirow{4}{*}{21} & $0.828^{* * *}$ & 0.000 & $-0.035^{* * *}$ & 0.046 & -3.405 & 0.003 \\
\hline & $n_{i 1}-n_{i 0}$ & & $0.775^{* * *}$ & 0.000 & $3.762 * * *$ & 2.827 & 6.099 & 0.000 \\
\hline & $a_{i 1}-a_{i 0}$ & & $0.694^{* * *}$ & 0.000 & $0.040^{* * *}$ & 0.059 & 3.125 & 0.005 \\
\hline & $d_{i 1}-d_{i 0}$ & & $0.848^{* * *}$ & 0.000 & -88.167 & 305.170 & -1.324 & 0.200 \\
\hline
\end{tabular}

*** significant at 0.01 .

\subsubsection{Test for Scenario 2}

Table 7 presents the results of the paired sample $t$-test for the change in the degree of LF in Scenario 2. When the degree of LF increases, the correlation coefficients of the LFI and the three individual indicators are greater than 0.49 and pass the significance test. When the degree of LF decreases, the correlation coefficients of the LFI and the other two individual indicators, in addition to the number of plots, are greater than 0.88 and pass the significance test. These results indicate that an increase or decrease in the degree of LF results in the data's high correlation before and after land transfer, so the paired sample $t$-test can be employed.

Consistent with the theoretical analysis, the $t$-tests demonstrated that the LFI in Scenario 2 may increase or decrease. The average number and size of the plots increase while the average distance between the plots may shorten or lengthen. The adjacency of the transferred plots to the contracted plots is a necessary condition but not a sufficient condition for the reduction in the degree of LF. However, even if the transferred and contracted plots are spatially adjacent, the problems of land ownership and the normalization of land transfer hinder merging and consolidation by the tenants. Therefore, land transfer aimed at preventing LF may be unsuccessful.

Table 7. Results of paired sample t-test for change of LF degree in scenario 2.

\begin{tabular}{|c|c|c|c|c|c|c|c|c|}
\hline & \multirow{2}{*}{$L F I_{i t}$} & \multicolumn{3}{|c|}{ Paired Samples Correlations } & \multicolumn{4}{|c|}{ Paired Sample Differences } \\
\hline & & Samples & Correlation & Sig. & Mean & Std. Dev. & $t$-Value & Sig. \\
\hline \multirow{4}{*}{ Increase } & $L F I_{i 1}-L F I_{i 0}$ & \multirow{4}{*}{24} & $0.893^{* * *}$ & 0.000 & $0.040 * * *$ & 0.027 & 7.133 & 0.000 \\
\hline & $n_{i 1}-n_{i 0}$ & & $0.728^{* * *}$ & 0.000 & $4.375^{* * *}$ & 3.437 & 6.237 & 0.000 \\
\hline & $a_{i 1}-a_{i 0}$ & & $0.847^{* * *}$ & 0.000 & 0.003 & 0.018 & 0.752 & 0.460 \\
\hline & $d_{i 1}-d_{i 0}$ & & $0.491^{* *}$ & 0.015 & 47.917 & 237.555 & 0.988 & 0.333 \\
\hline \multirow{4}{*}{ Decrease } & $L F I_{i 1}-L F I_{i 0}$ & \multirow{4}{*}{13} & $0.944^{* * *}$ & 0.000 & $-0.025 * * *$ & 0.018 & -5.121 & 0.003 \\
\hline & $n_{i 1}-n_{i 0}$ & & 0.418 & 0.155 & $2.077^{* *}$ & 2.499 & 2.997 & 0.011 \\
\hline & $a_{i 1}-a_{i 0}$ & & $0.948^{* * *}$ & 0.000 & 0.012 & 0.038 & 1.111 & 0.288 \\
\hline & $d_{i 1}-d_{i 0}$ & & $0.880^{* * *}$ & 0.000 & $\begin{array}{c}-396.154 \\
* * *\end{array}$ & 258.571 & -5.524 & 0.000 \\
\hline
\end{tabular}

** significant at $0.05, * * *$ significant at 0.01 .

\subsubsection{Test for Scenario 3}

Table 8 shows the results of the paired sample $t$-test for both the presence of changes (increase or decrease) and lack of changes in the number of plots in Scenario 3. When the number of plots increases, the correlation coefficients of the LFI and the average size of plots are greater than 0.56 but do not pass the significance test, whereas the correlation coefficients of the number of plots and the average distance between plots are greater than 0.78 and pass the significance test. When the number of plots does not change or decrease, the correlation coefficients of the LFI and the three individual indicators are greater than 
0.73 and pass the significance test, indicating that regardless of the presence or absence of a change in the number of plots, there is a significant correlation between the data before and after land transfer and consolidation, so the paired sample $t$-test can be employed.

Inconsistent with the theoretical analysis, the $t$-tests demonstrated that the LFI in Scenario 3 decreases significantly. When the average number of plots increases, the average size of the plots enlarges and the average distance between plots shortens, contributing to a significant decrease in the LFI. However, the theoretical analysis shows that when the number of plots increases, the change in the LFI is uncertain. The main reason for such an outcome is the small scale of operation and fragmented holdings of cultivated land, which result in lower agricultural productivity and incomes. When the transfer of cultivated land is allowed and the rent is within the acceptable range, farmers have incentives to transfer in the larger plots that are adjacent to the contracted plots, then merge and consolidate them. However, the keys to solving the problem of LF lie in the willingness of the landlords to let the tenants merge and consolidate their contracted plots, as well as the willingness of the tenants to do so. Therefore, the coupling effects of land transfer and consolidation are limited by strict matching conditions, as only $10.87 \%$ of the tenants have partially or completely merged and consolidated their transferred and contracted plots.

Table 8. Results of paired sample $t$-test for change of LF degree in scenario 3.

\begin{tabular}{|c|c|c|c|c|c|c|c|c|}
\hline & \multirow{2}{*}{$n_{i t}$} & \multicolumn{3}{|c|}{ Paired Sample Correlation } & \multicolumn{4}{|c|}{ Paired Sample Differences } \\
\hline & & Samples & Coefficient & Sig. & Mean & Std. Dev. & $t$-Value & Sig. \\
\hline \multirow{4}{*}{ increased } & $L F I_{i 1}-L F I_{i 0}$ & \multirow{4}{*}{8} & 0.611 & 0.107 & $-0.056^{* *}$ & 0.060 & -2.643 & 0.033 \\
\hline & $n_{i 1}-n_{i 0}$ & & $0.789 * *$ & 0.020 & $1.750 * * *$ & 1.035 & 4.782 & 0.002 \\
\hline & $a_{i 1}-a_{i 0}$ & & 0.566 & 0.144 & 0.057 * & 0.085 & 1.909 & 0.098 \\
\hline & $d_{i 1}-d_{i 0}$ & & $0.907^{* * *}$ & 0.002 & $-337.500 *$ & 492.624 & -1.938 & 0.094 \\
\hline \multirow{4}{*}{$\begin{array}{l}\text { unchanged } \\
\text { or } \\
\text { decreased }\end{array}$} & $L F I_{i 1}-L F I_{i 0}$ & \multirow{4}{*}{7} & $0.736^{*}$ & 0.096 & $-0.058 *$ & 0.060 & -2.386 & 0.063 \\
\hline & $n_{i 1}-n_{i 0}$ & & $0.741 *$ & 0.092 & -2.667 & 3.724 & -1.754 & 0.140 \\
\hline & $a_{i 1}-a_{i 0}$ & & 0.779 * & 0.068 & 0.130 & 0.200 & 1.601 & 0.170 \\
\hline & $d_{i 1}-d_{i 0}$ & & $0.903 * *$ & 0.014 & $-158.333 *$ & 185.517 & -2.091 & 0.091 \\
\hline
\end{tabular}

${ }^{*}$ significant at $0.1 ;{ }^{* *}$ significant at $0.05,{ }^{* * *}$ significant at 0.01 .

\section{Discussion}

\subsection{The Advantage of the New LFI}

There are two perspectives by which to measure the degree of LF: micro-farmer perspective $[3,5]$ and macro-region perspective $[8,10]$. From the perspective of the microfarmer, the measurement indicators of LF include the number, sizes, and distribution of plots. From the perspective of the macro-region, the selection of measurement indicators is generally based on GIS technology and landscape ecology. In addition to the number, size, and distribution of the landscape, its shape is considered. However, the macroregion perspective describes only the physical fragmentation of land and does not consider ownership fragmentation. In contrast, the micro-farmer perspective takes both the physical and ownership fragmentation into consideration. Additionally, farmers are the main force in land management and the core subject of fragmentation treatment in China, so it is more reasonable to select the measurement indicators of the degree of LF from the micro-farmer perspective.

The selection of the measurement indicators should be based on the attribute characteristics of LF, and the distribution of plots is based on the distances of each plot from other plots. Compared with the distances between plots and homesteads, the distances between plots can better reflect how the plots are spatially distributed. Therefore, we selected the number of plots, the average size of plots, and the average distance between plots as the measurement indicators of the degree of LF, then introduced the farmers' grading method to determine the weight coefficients of the three individual indicators, and finally employed the comprehensive index method to calculate the LFI. Compared with Simpson's, Januszewski's, and Igbozurike's index, the new index not only combines information on 
the number and sizes of plots but also combines information on the distribution of plots. In addition, this new index can also identify the contribution of a single indicator to the composite index. Therefore, the new index significantly outperforms the existing indices, which will lay a foundation for the study of degree, effect, and governance of LF.

\subsection{Policy Implications and Limitations}

The average LFI value of low mountain and hill areas is higher than that of low hillock and plain areas. In the low hillock and plain areas, the main causes of LF were property factors such as the land equalization system under the HCRS, followed by natural factors such as hydrological conditions; both of these ultimately left each household in possession of numerous small and separate plots of cultivated land. In the low mountain and hill areas, the main causes of LF were natural factors such as geomorphic conditions, followed by the property factors, which ultimately left each household in possession of many rugged and irregular-shaped plots of cultivated land. Therefore, the treatment measures for LF must be targeted and differentiated. In the low hillock and plain areas, the key to solving the fragmentation problem lies in promoting the benign interaction between labor force transfer and cultivated land transfer by strengthening the development of factor markets in rural areas, especially the labor force market and land transfer market. In the low mountain and hill areas, under the premise of minimizing excessive disturbance to the ecological environment, the land leveling projects should be carried out in accordance with local conditions, so as to form a unique and well-scattered landscape of "terraced filed" and "low slope hills". Additionally, it is necessary to accelerate the development of small agricultural machinery suitable for hilly and mountainous operations, and vigorously cultivate agricultural machinery specialized service households and agricultural machinery cooperative organizations.

The farmer-led land transfer and consolidation focus on solving the problem of LF faced by farmers, who decide for themselves whether to participate in land transfer and consolidation rather than being forced to join by the government, the village cadres, or the new types of agricultural business entities (NABE), such as leading agricultural enterprises and specialized farmers cooperatives. A community of shared interests is formed under the condition that farmers participate voluntarily so that land transfer and consolidation become an internal requirement of farmers. The control of LF has a broader public awareness. Farmer-led land transfer and consolidation internalize the complex problem of LF, which requires rational decisions made by different farmers after comprehensive weighing. However, intended to accelerate the cultivation of NABE, preferential policies, regardless of land transfer or consolidation, issued by the Chinese government tend to support the development of NABE while not paying enough attention to farmers. Although the NABE do play an important role in the treatment of LF, farmers are and will remain the main force in land management and the core subject of fragmentation treatment for a long time to come $[46,47]$. Therefore, the land transfer and consolidation dominated by the NABE could not be regarded as a solution to the problems faced by farmers. While maintaining smallholder operations, the government should provide more funding and technical support to farmers in order to encourage their participation in land transfer and consolidation as a solution to LF.

This study focus on the quantitative evaluation of LI Change before and after land transfer and consolidation led by rice farmers. However, the development degree of land transfer market in Wuhan metropolitan area is relatively low, and only 138 farmers participated in land transferred-in, accounting for $17.81 \%$ of the total number of samples. Therefore, it is not going to be possible to draw any robust conclusions from that small number of cases. However, this study aims to explain the observed phenomenon and reveal the underlying mechanism. The rationality of conclusions should be verified by using large-scale data covering different natural and socio-economic conditions. 


\section{Conclusions}

Wuhan metropolitan area presents a particularly interesting case for investigating LF, as it is a consequence of the The HCRS carried out in 1978 in China. The HCRS is considered as the most important cause of small operation and fragmented holding of cultivated land, and these two problems have persisted to the present day. Although there have been several studies on whether land transfer or consolidation reduces LF, no evidence exists for the effectiveness of farmer-led land transfer and consolidation. Hence, our study fills a gap in the literature by taking the Wuhan metropolitan area as a case study and analyzing the effectiveness of farmer-led land transfer and consolidation on LF. The main conclusions are summarized as follows.

No matter whether it is from individual indicators or from comprehensive index, there are spatial differences in degrees of LF. However, from the perspective of individual indicators, it is impossible to judge the degree of LF in different landform types. Contrarily, from the perspective of comprehensive index, it can be intuitively found that the fragmentation of low mountain and hill areas is higher than that of low hillock and plain areas.

There are neither positive nor negative relationships between the scale of land management and the degree of LF. Before and after land transfer, no obvious linear correlation exists between them. However, when small- and medium-scale farmers transform into large-scale farmers, the LFI is significantly reduced, indicating that farmers pay close attention to the treatment of LF in their pursuit of economies of scale in agricultural production.

The treatment of LF depends on the coupling effects of land transfer and consolidation. Land transfer caused the LFI to increase by $2.85 \%$, which means that relying solely on land transfer does not reduce LF and may even intensify it. The main reason is the non-adjacency of most transferred plots and contracted plots, so the tenants are unable to merge and consolidate them. Only spatially adjacent transferred plots and contracted plots that have been merged and consolidated can effectively reduce LFI.

Author Contributions: Conceptualization, C.Z.; methodology, C.Z.; validation, D.C.; formal analysis, C.Z.; investigation, C.Z.; writing—original draft preparation, C.Z.; writing-review and editing, D.C.; visualization, C.Z.; supervision, D.C.; project administration, D.C.; funding acquisition, D.C. All authors have read and agreed to the published version of the manuscript.

Funding: This research was funded by the Fundamental Research Funds for the Central Universities (grant number 2662020GGQD001); the Humanities and Social Sciences Research Project of the Ministry of Education (grant number 17YJC630225); the National Natural Science Foundation Project of China (grant number 41801190); the China Postdoctoral Science Fund Project (grant number 2020M672365); and the Hunan Provincial Natural Science Foundation of China (grant number 2019JJ50390).

Institutional Review Board Statement: Not applicable.

Informed Consent Statement: Not applicable.

Data Availability Statement: The data that support the findings of this study are available from the first author Chaozheng Zhang, upon reasonable request.

Acknowledgments: We are thankful to Yulong Li for English language editing. We also extend great gratitude to the anonymous reviewers and editors for their helpful reviews and critical comments.

Conflicts of Interest: The authors declare no conflict of interest.

\section{References}

1. Austin, O.C.; Ulunma, A.C.; Sulaiman, J. Exploring the link between land fragmentation and agricultural productivity. Int. J. Agric. For. 2012, 2, 30-34.

2. Tenna, A.G.; Zewdu, B.A.; Assefa, A.B. Effects of land fragmentation on productivity in Northwestern Ethiopia. Adv. Agri. 2017, 1-9. [CrossRef]

3. Latruffe, L.; Piet, L. Does land fragmentation affect farm performance? A case study from Brittany, France. Agric. Syst. 2014, 129, 68-80. [CrossRef]

4. Postek, P.; Leń, P.; Stręk, Ż. The proposed indicator of fragmentation of agricultural land. Ecol. Indic. 2019, 103, 581-588. [CrossRef] 
5. Tan, S.; Heerink, N.; Kruseman, G.; Qu, F. Do fragmented landholdings have higher production costs? Evidence from rice farmers in Northeastern Jiangxi province, PR. China. China Econ. Rev. 2008, 19, 347-358. [CrossRef]

6. Orea, L.; Perez, J.A.; Roibas, D. Evaluating the double effect of land fragmentation on technology choice and dairy farm productivity: A latent class model approach. Land Use Policy 2015, 45, 189-198. [CrossRef]

7. Falco, S.D.; Penov, I.; Aleksiev, A.; Rensburg, T.M.V. Agrobiodiversity, farm profits and land fragmentation: Evidence from Bulgaria. Land Use Policy 2010, 27, 763-771. [CrossRef]

8. Mekki, I.; Bailly, J.S.; Jacob, F.; Chebbi, H.; Ajmi, T.; Blanca, Y.; Zairi, A.; Biarnes, A. Impact of farmland fragmentation on rainfed crop allocation in Mediterranean landscapes: A case study of the Lebna watershed in Cap Bon, Tunisia. Land Use Policy 2018, 75, 772-783. [CrossRef]

9. Ntihinyurwa, P.D.; de Vries, W.T.; Chigbu, U.E.; Dukwiyimpuhwe, P.A. The positive impacts of farm land fragmentation in Rwanda. Land Use Policy 2019, 81, 565-581. [CrossRef]

10. Qiu, L.; Zhu, J.; Pan, Y.; Wu, S.; Dang, Y.; Xu, B.; Yang, H. The positive impacts of landscape fragmentation on the diversification of agricultural production in Zhejiang province, China. J. Clean Prod. 2020, 251, 119722. [CrossRef]

11. Hung, P.V.; MacAulay, T.G.; Marsh, S.P. The economics of land fragmentation in the north of Vietnam. Aust. J. Agric. Resour. Econ. 2007, 51, 195-211. [CrossRef]

12. Rahman, S.; Rahman, M. Impact of land fragmentation and resource ownership on productivity and efficiency: The case of rice producers in Bangladesh. Land Use Policy 2009, 26, 95-103. [CrossRef]

13. Tan, S.; Heerink, N.; Kuyvenhoven, A.; Qu, F. Impact of land fragmentation on rice producers' technical efficiency in South-East China. NJAS-Wagen. J. Life Sci. 2010, 57, 117-123. [CrossRef]

14. Lu, H.; Xie, H.; He, Y.; Wu, Z.; Zhang, X. Assessing the impacts of land fragmentation and plot size on yields and costs: A translog production model and cost function approach. Agric. Syst. 2018, 161, 81-88. [CrossRef]

15. Lu, H.; Xie, H.; Yao, G. Impact of land fragmentation on marginal productivity of agricultural labor and non-agricultural labor supply: A case study of Jiangsu, China. Habitat Int. 2019, 83, 65-72. [CrossRef]

16. Veljanoska, S. Can land fragmentation reduce the exposure of rural households to weather variability? Ecol. Econ. 2018, 154, 42-51. [CrossRef]

17. Wang, Y.; Zang, L.; Araral, E. The impacts of land fragmentation on irrigation collective action: Empirical test of the socialecological system framework in China. J. Rur. Stud. 2020, 78, 234-244. [CrossRef]

18. Zhang, B.; Niu, W.; Ma, L.; Zuo, X.; Kong, X.; Chen, H.; Zhang, Y.; Chen, W.; Zhao, M.; Xia, X. A company-dominated pattern of land consolidation to solve land fragmentation problem and its effectiveness evaluation: A case study in a hilly region of Guangxi Autonomous Region, Southwest China. Land Use Policy 2019, 88, 104015. [CrossRef]

19. Zhou, J.; Cao, X. What is the policy improvement of China's land consolidation? Evidence from completed land consolidation projects in Shaanxi Province. Land Use Policy 2020, 99, 104807. [CrossRef]

20. Nguyen, H.Q.; Warr, P. Land consolidation as technical change: Economic impacts in rural Vietnam. World Dev. 2020, 127, 104750. [CrossRef]

21. Munnangi, A.K.; Lohani, B.; Misra, S.C. A review of land consolidation in the state of Uttar Pradesh, India: Qualitative approach. Land Use Policy 2020, 90, 104309. [CrossRef]

22. Sklenicka, P.; Janovska, P.; Salek, M.; Vlasak, J.; Molnarova, J. The Farmland Rental Paradox: Extreme land ownership fragmentation as a new form of land degradation. Land Use Policy 2014, 38, 587-593. [CrossRef]

23. Liu, Y.; Yan, B.; Wang, Y.; Zhou, Y. Will land transfer always increase technical efficiency in China?-A land cost perspective. Land Use Policy 2019, 82, 414-421. [CrossRef]

24. Awasthi, M.K. Dynamics and resource use efficiency of agricultural land sales and rental market in India. Land Use Policy 2009, 26, 736-743. [CrossRef]

25. Rahman, S. Determinants of agricultural land rental market transactions in Bangladesh. Land Use Policy 2010, $27,957-964$. [CrossRef]

26. Min, S.; Waibel, H.; Huang, J. Smallholder participation in the land rental market in a mountainous region of Southern China: Impact of population aging, land tenure security and ethnicity. Land Use Policy 2017, 68, 625-637. [CrossRef]

27. Zhang, L.; Feng, S.; Heerink, N.; Qu, F.; Kuyvenhoven, A. How do land rental markets affect household income? Evidence from rural Jiangsu, P.R. China. Land Use Policy 2018, 74, 151-165. [CrossRef]

28. Li, R.; Li, Q.; Lv, X.; Zhu, X. The land rental of Chinese rural households and its welfare effects. China Econ. Rev. 2019, 54, 204-217. [CrossRef]

29. Kijima, Y.; Tabetando, R. Efficiency and equity of rural land markets and the impact on income: Evidence in Kenya and Uganda from 2003 to 2015. Land Use Policy 2020, 91, 104-416. [CrossRef]

30. Lohmar, B.; Zhang, Z.; Somwaru, A. Land rental market development and agricultural production in China. In Proceedings of the Annual Meetings of the American Agricultural Economics Association, Chicago, IL, USA, 4-8 August 2001.

31. Deininger, K.; Jin, S. The potential of land rental markets in the process of economic development: Evidence from China. J. Dev. Econ. 2005, 75, 241-270. [CrossRef]

32. Ma, X.; Heerink, N.; Lerland, E.V.; Lang, H.; Shi, X. Decisions by Chinese households regarding renting in arable land: The impact of tenure security perceptions and trust. China Econ. Rev. 2020, 60, 101328. [CrossRef] 
33. Wang, Y.; Li, X.; He, H.; Xin, L.; Tan, M. How reliable are cultivated land assets as social security for Chinese farmers? Land Use Policy 2020, 90, 104318. [CrossRef]

34. Liu, J.; Jin, X.; Xu, W.; Sui, R.; Han, B.; Yang, X.; Gu, Z.; Xu, C.; Sun, X.; Zhou, Y. Influential factors and classification of cultivated land fragmentation, and implications for future land consolidation: A case study of Jiangsu Province in eastern China. Land Use Policy 2019, 88, 104185. [CrossRef]

35. Muchová, Z.; Raškovič, V. Fragmentation of land ownership in Slovakia: Evolution, context, analysis and possible solutions. Land Use Policy 2020, 95, 104644. [CrossRef]

36. Liu, Y.; Li, Y. China's land creation project stands firm. Nature 2014, 548, 275-277. [CrossRef] [PubMed]

37. Niroula, S.G.; Thapa, G.B. Impacts and causes of land fragmentation, and lessons learned from land consolidation in South Asia. Land Use Policy 2005, 22, 358-372. [CrossRef]

38. Qiu, T.; Choy, S.T.B.; Li, S.; He, Q.; Luo, B. Does land renting-in reduce grain production? Evidence from rural China. Land Use Policy 2020, 90, 104311. [CrossRef]

39. Zhang, Y.; Halder, P.; Zhang, X.; Qu, M. Analyzing the deviation between farmers' land transfer intention and behavior in China's impoverished mountainous area: A Logistic-ISM model approach. Land Use Policy 2020, 94, 104534. [CrossRef]

40. Statistical Bureau of Hubei Province; Survey Office of the National Bureau of Statistics in Hubei. Hubei Statistical Yearbook 2016; China Statistics Press: Beijing, China, 2016.

41. Gao, X.; Zhang, A.; Sun, Z. How regional economic integration influence on urban land use efficiency? A case study of Wuhan metropolitan area, China. Land Use Policy 2020, 90, 104329. [CrossRef]

42. You, H. Agricultural landscape dynamics in response to economic transition: Comparisons between different spatial planning zones in Ningbo region, China. Land Use Policy 2017, 61, 316-328. [CrossRef]

43. Rietveld, T.; Hout, R.V. The paired t test and beyond: Recommendations for testing the central tendencies of two paired samples in research on speech, language and hearing pathology. J. Commun. Disord. 2017, 69, 44-58. [CrossRef] [PubMed]

44. Mee, R.W.; Chua, T.C. Regression toward the mean and the paired sample $t$ test. Am. Statis. 1988, 45, 39-42. [CrossRef]

45. Xue, W. Statistical Analysis and SPSS Application; Renmin University of China Press: Beijing, China, 2013. (In Chinese)

46. Sun, X.; Zhou, P.; Zeng, F. Self-governing mechanism of land fragmentation: Based on the Case Study of W County, Shandong Province. Issues Agric. Econ. 2020, 9, 122-131. (In Chinese)

47. Zhang, B.; Niu, W.; Zuo, X.; Kong, X.; Yun, W.; Chen, H. Farmer-dominated pattern land consolidation to solve arable land fragmentation and its effectiveness evaluation in Guangxi. Trans. CSAE 2019, 35, 265-274. (In Chinese) 